\title{
TIEMPO Y ESPACIO EN LA LÍRICA: EL CASO DE JAIME GIL DE BIEDMA
}

LUIS BELTRÁN ALMERÍA

Universidad de Zaragoza

El tiempo es uno de los aspectos temáticos más importantes y mejor estudiados en poesía. La poesía española contemporánea no es una excepción ${ }^{1}$. Una importante reflexión sobre el tiempo fluye del pensamiento poético. Gil de Biedma apenas ha llamado la atención de los estudiosos de la retórica del tiempo, si no es por aspectos derivados: el sentimiento de irrealidad -en J. O. Jiménez 1972a y 1991 - o la llamada poesía de la experiencia -aspecto este último que no se suele ver relacionado con nuestra temática tempo-espacial-.

Sin embargo, no es éste el tema que queremos abordar aquí. O, al menos, no se trata del enfoque que le queremos dar. Nuestro tema pretende no disociar el tiempo y el espacio, y, al mismo tiempo, no reducir el problema a su dimensión temática, sino tratarlo en toda su dimensión artística. En otras palabras, la tarea que proponemos es la de analizar el tipo de asimilación que se da en la obra de Gil de Biedma del espacio y del tiempo y caracterizar al hombre que se conforma en ese marco. El proceso de asimilación de los diversos aspectos del espacio y del tiempo accesibles en los respectivos estados evolutivos de la hu-

1 J. O. JimÉnEz, en Cinco poetas del tiempo (1972), traza una panorámica de las vicisitudes del tema temporal en la poesía española contemporánea. El eje sobre el que gira este libro es la idea de que el tiempo constituye el gran tema de la poesía hispana contemporánea. Esta idea está convenientemente matizada por J. O. Jiménez en el prólogo de su libro. 
manidad ha dado lugar en el arte y en la literatura a una historia compleja y discontinua. La literatura y sus diversos géneros han ido elaborando métodos para la reflexión y realización artística de los aspectos asimilados de la realidad histórica. Comprenderlos, o al menos, acercarnos a ellos, es nuestro propósito.

Recientemente A. J. Greimas y J. Fontanille (1991) han expuesto un notable esfuerzo por acercarse con un discurso creativo a problemas no muy distintos a los que aquí se plantean: «La sémiotique est et doit rester, pour ne pas perdre son âme, un projet scientifique situé a "échelle humaine"》 (GreimasFontanille, 1991: 324). Pero en un aspecto mi proyecto difiere sustancialmente del programa greimasiano. Mientras la semiótica estructural se aferra con fuerza a un fundamento linguístico (las parejas modalización/aspectualización y tensivité(phorie), esta investigación se funda en una reflexión sobre conceptos como género literario, modernidad y persona.

La tradición - tanto estructuralista, como idealista- no ha visto relación entre espacio y tiempo y menos que esa relación estuviese impresa en el corazón de la obra literaria. El estructuralismo reduce su análisis a una oposición interior/exterior para el espacio y a un conjunto de posibilidades sobre duración y orden, en la dimensión temporal. Estas concepciones contrastan con los testimonios de algunos artistas -entre ellos, los del propio Gil de Biedma- y con una visión solidaria del problema de espacio-tiempo, la de Bajtín, que, hasta hoy, se presenta solitaria en el panorama de los estudios literarios ${ }^{2}$.

2 BATTh propuso una categoría, la de cronotopo, que define como «conexión esencial de relaciones temporales y espaciales asimiladas artísticamente en literatura" (BAJTiN, 1975: 237). Y algo más adelante vuelve con otra definición con palabras algo más concisas: «unión de elementos espaciales y temporales en un todo inteligible y concreto" (p. 237). Esta unión de elementos aparece claramente en los diversos tipos de novela y Bajtín le dedico un extenso estudio. Me refiero a «Las formas del tiempo y del cronotopo en la novela», en Bajtín (1975: 237-410). En la novela el tiempo se condensa y se vuelve visible desde un punto de vista artístico y el espacio se intensifica, penetra en el movimiento del tiempo, del argumento, de la narración. Así es como el espacio se hace tiempo y el tiempo se hace espacio. Como ejemplo valga el cronotopo que Bajtín denomina del castillo. En el espacio del castillo todo objeto adquiere una especial relación con el pasado, con la historia, tanto dentro, como en los alrededores. El tiempo adquiere en ese espacio un claro sentido histórico. Ese es el espacio-tiempo de la novela histórica.

Este método de análisis del espacio y del tiempo ha permitido a Bajtín determinar los principales tipos de novela, desde los más antiguos hasta la contemporaneidad y según el pensador ruso debe permitir analizar cualquier género y sus variedades. Una comprensión acabada del papel del cronotopo nos debe permitir comprender cómo determinados géneros persisten obstinadamente cuando ya han perdido definitivamente su significación histórica. Sin embargo, el mismo Bajtín no produjo un desarrollo de su concepción del cronotopo a un género que no fuera la novela y en sus obras no podemos encontrar ni siquiera huellas de los problemas que suscita la aplicación del análisis cronotópico en otros géneros. 
Si un género ha sido tradicionalmente interpretado como intemporal es la poesía. La concepción de la intemporalidad de la lírica está mucho más enraizada en la teoría literaria de lo que muchos estudiosos juzgan razonable aceptar. R. Langbaum (1957) ha sido uno de los pocos en proponer una concepción temporal de la lírica. En cambio, la concepción de la intemporalidad y esencialidad poéticas siempre ha tenido adeptos y nunca ha sido seriamente cuestionada. No es de extrañar esta situación. Pese a la actual abundancia de literatura sobre los géneros, arrastramos una parquedad alarmante de estudios teóricos sobre el problema de la lírica. Y lo mismo que hoy seguimos estancados en la línea de la clásica concepción tripartita de los géneros -drama, épica y lírica-, somos rehenes de una formulación de la lírica expresada hace doscientos años. Dice Hegel en su Estética:

La poesía lírica satisface una necesidad completamente opuesta [a la épica, que es narrativa]; la de expresar lo que sentimos, y contemplarnos nosotros mismos en la manifestación de nuestros sentimientos (Estética, II, 401).

Palabras éstas que para muchos parecen mantener hoy una validez intemporal. Un contemporáneo, Todorov, cuando quiere darnos un diagnóstico sobre el conocimiento actual de los géneros líricos, recurre a F. Schlegel:

Las divisiones usuales de la poesía no son nada más que compartimentación muerta para un horizonte limitado (...). Quizás ha llegado el momento de poner en práctica el programa de Friedrich Schlegel (Todorov, 1987: 40).

El programa de Schlegel es «reemplazar el universo precopernicano por un sistema plenamente dinámico». Y, efectivamente, esa es hoy la tarea, no sólo en el dominio de los géneros líricos, sino en el conjunto de los géneros literarios. Pero es ciertamente en el dominio lírico donde el sistema estático precopernicano sobrevive con mayor desahogo. Las razones quizá haya que buscarlas en esa concepción de lo lírico que Hegel resumió con tanto tino que ha llegado hasta nosotros incorrupta. Dice la sabiduría popular que no hay 
mentiras más peligrosas que las verdades a medias, y la definición hegelianoromántica de la lírica es una gran verdad a medias.

Es verdad porque es cierto que el patetismo es la estética fundamental de los géneros líricos, pero es insuficiente en tanto en cuanto el sentimentalismo no agota el dominio de los géneros líricos ni se agota en ellos. Esa insuficiencia ha provocado reacciones en dos sentidos opuestos: los que han buscado una reformulación de lo lírico en un orden más conceptual y restringido $-\mathrm{y}$, por tanto, capaz de ampliar el dominio lírico-; y los que se han inclinado por posiciones empíricas en las antípodas del doctrinarismo de los primeros. Los primeros se han replegado sobre las teorizaciones del yo-lírico, teorizaciones idealistas que vuelven la espalda al aspecto histórico de la cuestión. K. Hamburger sería una excelente representante de esta posición, teorizando el yo-lírico como sujeto de una enunciación no ficticia ${ }^{3}$. La segunda posición domina hoy el panorama de la historia de la lírica y entre no pocos teóricos. Citaré a modo de ejemplo la siguiente explicación de la ampliación del objeto lírico; la de Peter Dronke en el Prefacio a su conocido estudio La lírica en la Edad Media:

La lírica incluida es tan variada que espero se me perdone por no empezar con una discusión o una definición de la naturaleza de la lírica. El objeto de mi estudio es el contenido de los cancioneros o Liederhandschriften de la Edad Media con toda su diversidad, considerando «lírico» todo lo que está contenido en ellos o guarde con ellos una semejanza esencial. Desearía que no resultase vana mi esperanza de que la misma variedad de la poesía citada y estudiada más adelante puede contribuir a enriquecer nuestro concepto de la lírica (Dronke, 1968: 12).

El empirismo ha sido siempre el principio fundamental del historicismo positivista, unas veces para bien y otras para mal. Entre los teóricos el principio empírico se halla también muy extendido, justificado normalmente por la idea del género como institución en la que la sociedad reconoce los mensajes culturales. El tópico del género como institución está tan extendido que es difícil misión señalar la paternidad de su autoría, lo que indica bien a las claras hasta qué punto es una idea de los tiempos que corren.

3 Aunque sólo K. Hamburger (1957) haya teorizado la exclusión de la lírica del dominio de la ficción literaria, la actitud de equiparar ficción con narración está amplísimamente representada en el panorama de los estudios literarios. 
Pero ambas direcciones de rectificación de la idea hegelorromántica de la lírica se agotan en la misma cuestión: su incapacidad para dar una idea tan profunda de la lírica como género que responda a las preguntas de T. Todorov:

¿Debe ser dividida la poesía, pura y simplemente?, ¿o debe considerarse una e indivisible?, ¿o pasar alternativamente de la división a la unión? (Todorov, 1987: 40).

Esto es, volvemos al reto de una concepción copernicana de los géneros líricos.

La revolución copernicana de los géneros líricos es imposible si no se basa en la combinación del papel que desempeña orgánicamente - y no como tema elegible - el espacio y el tiempo en la arquitectura de estos géneros, aspecto que no es privativo de estos géneros. El papel de Copérnico en los géneros literarios lo ha de desempeñar la Historia; pretender reducir cualquier cuestión al ámbito plano de una lógica elemental es condenarse al mundo ptolemaico.

Sin embargo, y por paradójico que parezca, un intento de redefinir los géneros líricos apoyándose en la asimilación artística - y no sólo temática- de la idea de espacio-tiempo ha de empezar por reconocer la lírica como un género artístico cuyo canon exige llevar la palabra más allá del tiempo, sacralizarla. En efecto, la lírica pertenece al club de los géneros elevados: la épica, la tragedia y la lírica, son los tres géneros canónicos ${ }^{4}$. Y, en estos géneros, y especialmente en el canon de la lírica, no cabe un tiempo presente no jerarquizado, el tiempo de la actualidad. Aunque los temas elegidos por los géneros líricos no pertenezcan a un pasado remoto, el tratamiento que reciben los sitúa de inmediato lejos del alcance de las fuerzas vivas del presente, los sacraliza. La forma de actuar del poeta consiste en elogiar a una persona o personas de manera que se establece una jerarquización tal que los «héroes» resultan transportados a un dominio inalcanzable. Este dominio se encuentra tan lejos del alcance del presente vivo como el pasado absoluto de la épica. Es más, en la poesía greco-latina clásica y en la poesía europea clásica bastaba con transpo-

4 Esta distinción entre géneros altos y bajos fue desarrollada en el formalismo ruso. B. TOMACHEVSKI (1928: 213) equipara esta situación con la evolución social «en el curso de la cual las clases "altas", dominantes, son gradualmente sustituidas por los estratos democráticos, bajos». 
ner los personajes al mundo remoto de los dioses clásicos para conseguir esa atmósfera sacralizada.

El objeto de la lírica, a diferencia de la épica, es un cierto tipo de presente, un presente jerarquizado e inalcanzable al común de los mortales; un presente distinto, reevaluado, ascendido al valor del pasado, perfecto. Este nuevo tipo de presente no forma parte del devenir accidental del tiempo, sino que aspira a convertirse en leyenda, en memoria, sub specie aeternitatis.

Pero no es este el momento para proponer un cuadro detenido del canon lírico; bastan unas primeras apreciaciones para mostrar la distancia que existe entre canon lírico y la "lírica» de Jaime Gil de Biedma. Biedma es un poeta moderno, plenamente consciente de su modernidad —de ahí su profunda admiración por Baudelaire o por Auden-. Pero la expresión "poeta moderno" encierra en sí misma un violento oxímoron, una explosiva contradicción: no es ya posible el lenguaje sagrado de la poesía en la modernidad. Naturalmente este fenómeno afecta a todas las facetas de la personalidad creadora de Gil de Biedma. Aquí lo vamos a analizar solamente en la dimensión espacio-temporal, que como ya hemos advertido reiteradamente condiciona desde los fundamentos artísticos del género lírico hasta su contenido temático ${ }^{5}$.

\section{ESPACIO Y TIEMPO EN BIEDMA}

Abordaremos en primer lugar la expresión de la concepción temático-simbólica que adquieren espacio y tiempo en Las personas del verbo. De ahí intentaremos remontarnos a las implicaciones genéricas y artísticas.

5 Pere Rovira da una explicación distinta de la relación de la poesía con lo sagrado:

La historia de la poesía modema, que empieza en el Romanticismo, tiene en su base el intento de llenar el hueco dejado por la «muerte» de Dios, y es precisamente la falta de un principio sagrado universal lo que precipita la vuelta del poeta moderno hacia lo «sagrado personal». Al sucumbir la explicación religiosa del mundo, la poesía recupera su papel de recurso mítico: cuando el mundo da la espalda a lo sagrado, la poesía lo reivindica (RoviRA, 1986: 13).

Esta argumentación viene al hilo de la justificación de una frase de Biedma reivindicando como tema fundamental de la poesía lo sagrado personal. Conecta directamente con la idea, frecuente en la filosofía y en la crítica literaria actuales, de la poesía como lenguaje primordial (uno de los más conocidos exponentes de esta idea es M. HEIDEGGER, «Hólderlin y la esencia de la poesía y «El origen de la obra de arte»). 
Lógicamente, la presencia de elementos espacio-temporales en la poesía de Biedma no ha pasado desapercibida a la crítica.

Para R. Sanger (1986: 93) el héroe biedmiano intenta conservar, como puede, una difícil serenidad ante la angustia producida por el espacio del tiempo. Esta angustia aparece simbolizada por un boquete; así, en «Arte poética»:

el vértigo del tiempo,

el gran boquete abriéndose hacia dentro del alma

por una sima en «Recuerda»:

... donde va, precipitado,

para siempre sumiéndose en el pasado.

que expresaría el «horrible dinamismo» del pasado, que convierte el presente en pasado y el pasado en olvido. Las observaciones de Sanger resultan interesantes y acertadas, pero insuficientes.

Antonio Jiménez Millán (1986) ha llamado la atención sobre el contenido familiarmente urbano de la poesía de Jaime Gil de Biedma y su carácter cerrado. También señala el rechazo urbano de Poemas póstumos, asociado a una rutina difícilmente soportable. Estas observaciones son justas, pero pertenecen a la parte temática del problema. Nada dicen del espacio y del tiempo estéticos, poemáticos, sino del espacio y tiempo que son puro contenido. Lo mismo ocurre con las observaciones sobre el tiempo de Sh. Mangini (1980: 96-114). Contemplados así, el espacio y el tiempo serían dos realidades que poco parecen tener que ver. Y para la arquitectura poética, la categoría del espacio-tiempo es una e indivisible y conforma la realidad profunda de todos los aspectos de la obra. Las citas de "Arte poética» y «Recuerda», sin embargo, nos presentan en sólo dos líneas un espacio-tiempo perfectamente fundidos: un espacio, el boquete, la sima, lo que Bajtín llamaría el umbral, identificado por un tiempo, la instantaneidad que separa presente y pasado. El espacio-tiempo de Las personas del verbo y de todo Biedma se caracteriza por la simultaneidad de procesos y la umbralidad de los espacios. 
La simultaneidad viene dada por la inmediatez de las voces personales de la poesía de Biedma ${ }^{6}$. No hay una evolución poética, una evolución del pensamiento poético. Nadie la ha señalado y, al contrario, las lecturas suelen ver la personalidad de Biedma relativamente completa ya en Compañeros de viaje. Sólo las etapas inicial y final de su poesía escapan a esa personalidad. Las voces confluyen, incluso todas, en muchos poemas conformando ese tipo especial de diálogo que Biedma y muchos críticos llaman monólogo dramático. La actividad memorial de Narciso hace confluir en un sólo plano presente y pasado. Si el pasado engulle el presente a través de una sima, la memoria es otra salida de los infiernos, que permite la recuperación del pasado. El ahora en el presente es el único plano posible en los poemas de Biedma.

El papel del umbral es trascendental para comprender la estética de Jaime Gil. No sólo la sima es un umbral. Sus escenarios son umbrales: por ejemplo, las afueras, de su prehistoria multipersonal. La preferencia de ciertos paisajes campestres - La Nava de la Asunción, Ultramort- se formaliza a través de la memoria como un umbral traído sobre la rutina urbana. Sus testimonios avalan que «el hecho de vivir cinco días a la semana en una ciudad» tiene una influencia directa no sólo en los paisajes urbanos que pueblan su poesía, sino en su atracción por la frontera entre la vida burguesa y la «vie de chateau». El interés por las despedidas — «En una despedida»-, por lo instantáneo, por lo pasajero (el final de «París, postal del cielo»: y aquel viaje camino de la cama- I en un vagón del metro Étoile-Nation). Y, finalmente, ese gusto por los espacios típicamente umbralísticos: los balcones, ventanas, pretiles; imágenes, aparentemente sorprendentes, que afloran constantemente en sus poemas. En la solapa de Las personas del verbo ya tenemos: Mitad Calibán. mitad Narciso le temo sobre todo cuando le escucho interrogarme junto a un balcón abierto... El mismo balcón aparece en «Las Afueras» VII, desde el balcón por donde entró la noche; en «Noches del mes de junio», junto al balcón abierto de par en par (la calle...); en «Vals de aniversario», Has dejado el balcón; en «Sábado», la piedra / mansa, la paciencia del pretil; en «Piazza del Popolo», Estaba el balcón abierto / igual que hoy está, de par / en par. En «Mañana de ayer, de hoy», En la abierta ventana / contemplándola, descansa. En «En el castillo de Luna», los años de cárcel son un boquete en el alma / que no puedes tapar nunca / una mina de amargura / y

6 En «El misterio trinitario de Jaime Gil de Biedma», comunicación leída en el Congreso «Jaime Gil de Biedma y su generación poética», Zaragoza, octubre de 1991, he expuesto mi teoría de las tres voces que conforman Las personas del verbo: Calibán -el esclavo indómito de The Tempest de Shakespeare-, que es la voz del hombre de la vida; Narciso, la voz de la memoria, y el Big Brother moralista. 
espantosa irrealidad. En «Elegía y recuerdo de la canción francesa», con la luna asomando tras las ventanas rotas. En «Ha venido a esa hora», Ventanas encendidas / la agrandan la tristeza. En «Ultramort», Me asomaré callado a ver el día.

El párrafo final de «Aunque sea un instante» - también el umbral en este título- resulta esclarecedor de la estética del umbral y ha llamado la atención de José Olivio Jiménez (1991) sobre el valor programático de este poema:

... gritamos (...) para creer (...) que la vida es más que esta pausa inmensa / vertiginosa / cuando la propia vocación (...) / vemos que no era más / que un desolador deseo de esconderse. Pausa inmensa, vertiginosa, esa es la percepción biedmiana de la vida; no caben, pues, otras concepciones del espaciotiempo que respondan a esta visión del umbral. Pero, además, resulta que la poesía es «sólo un desolador deseo de esconderse», de hurtarse al vértigo y la inmensidad del umbral.

Instalarse en lo simultáneo, en lo instantáneo, es una forma de combatir la velocidad, el vértigo. Es la única respuesta inteligente. La estética goetheana - la del ciclo Wilhelm Meister - o tolstoiana, basada en la evolución y aprendizaje del personaje resulta inapropiada para los requerimientos estéticos del siglo XX y para las tareas que se marca Gil de Biedma.

En el Retrato... esta percepción estética de la umbralidad y de la simultaneidad está magníficamente expresada en esta argumentación sobre el carácter de las ciudades:

El carácter cerradamente urbano de Barcelona (...) su aislamiento del campo (...), su radical diversidad (...) me produce malestar. Manila deja ver lo que rodea (...). Tiene la provisionalidad de las posadas: se está allí siempre de paso, lo justo para ser libre. Cada día es el primero y el último. Aquí, en cambio, resulta irremediable pensar en antes de ayer y en pasado mañana (p. 123).

Puede resultar paradójica la equiparación de intransitividad espacial de Barcelona con su transitividad temporal: el presente es mero tránsito del ayer al mañana. En cambio la transitividad espacial de Manila la equipara con la intransitividad temporal de sus días. Y la lectura antitética que se desprende de ambas paradojas - umbralidad es libertad, permanencia es dependencia- ilustra la profundidad de esta concepción estética. 


\section{LA POESÍA DE LA EXPERIENCIA}

Pero nos interesa ahora ver cómo esta concepción artística del espaciotiempo se traduce, no en símbolos, en aspectos más o menos relevantes, sino en la concepción misma de la obra de arte. Y precisamente sobre esta dimensión fundamental de la creación literaria biedmiana conviene que retomemos su reivindicación de la poesía de la experiencia, concepto íntimamente ligado al nombre de $R$. Langbaum.

La reivindicación biedmiana de la poesía de la experiencia va indisolublemente ligada a la denuncia de la vieja poesía. La genealogía de esa poesía de la experiencia arranca en España de Espronceda y Bécquer y continúa ya en este siglo con Unamuno y Cernuda (El pie de la letra, 341 y ss.). El siguiente salto genealógico llevaba a Gil de Biedma a su propia poesía. En un mundo sin fronteras, Gil de Biedma reconocía en Blake, Coleridge, Wordsworth, Leopardi, Goethe y Holderlin a los primeros poetas modernos: «los fundadores de la poesía que nosotros hacemos" (Ibid, 344). Caracteriza Biedma esta modemidad partiendo de dos pilares: romanticismo y «asimilación de la problemática humana» ${ }^{7}$. La explicación del nexo que puede unir conceptos en apariencia tan dispares podemos verla en la siguiente definición de lo que debe ser un poema moderno:

Un poema moderno no consiste en una imitación de la realidad o en un sistema de ideas acerca de la realidad - lo que los clásicos llamaban una imitación de la naturaleza - , sino en el simulacro de una experiencia real (Ibid, 342).

Esta definición revela una cierta inconsistencia teórica: a una débil caracterización de la poesía clásica enfrenta una endeble concepción de la poesía moderna. Pero tal inconsistencia sólo en parte -en la medida en que Biedma la asume- es responsabilidad de Gil de Biedma, porque la autoría de esta idea pertenece a Robert Langbaum, cuyo libro The Poetry of Experience es para Biedma una especie de poética aristotélica ${ }^{8}$. Langbaum concibe dos grandes

7 Ambos conceptos - romanticismo y personalismo- tienen por fundamento el individualismo que caracteriza el pensamiento moderno, frente al carácter dogmático-colectivo del racionalismo.

8 El mismo Langbaum sugiere el paralelismo entre su obra y la Poética de Aristóteles en sus conclusiones (LANGBAUM, 1957: 210). 
corrientes en la historia de la poesía: la clásica y la moderna. La clásica sería una poesía ideológica, basada en la imitación de un sistema externo y ajeno de ideas. La poesía moderna privilegia la experiencia sobre la idea, pues la experiencia da lugar a una «imaginación» cierta y primaria, mientras que la reflexión analítica que la sigue es secundaria y problemática. Estas dos grandes corrientes poéticas tienen su frontera en el mundo de la Ilustración y, para Langbaum, de ella surge el movimiento de la poesía moderna que él denomina Romanticismo y en el que caben estéticas contrapuestas, pero que comparten una misma retórica de la experiencia ${ }^{9}$. La estética romántica admite tal grado de simetría y contradicción entre sus diversas ramas que aquellos poetas que pretenden romper con ella abrazando un sistema dogmático también participan en su fundamentación empirista. Yeats con su cosmología, Eliot con su anglocatolicismo, y el Auden de los años 30 con su marxismo no consiguen desprenderse -independientemente de su éxito o fracaso- de su herencia romántica.

La concepción del Romanticismo equiparado a modernidad es sugerente y, no en vano, el libro de Langbaum ha adquirido cierta aureola de clásico. Pero la aplicación que hace de esta teoría Biedma adolece de dos problemas: uno, el de la transposición al mundo hispánico que hace Biedma; $y$, dos, el de la propia fundamentación de la teoría de Langbaum. Vayamos con el primero, la aplicación biedmiana de la poesía de la experiencia a la historia poética española. El corte histórico que Langbaum propone con la Ilustración tiene un perfil nítido y profundo, divide claramente la historia de la poesía en dos épocas: clasicismo y romanticismo. La aplicación de este corte histórico para la poesía española resulta todo lo contrario, hasta el mismo Gil de Biedma sólo hay excepciones románticas; Espronceda, quizá Bécquer, Unamuno y Cernuda - pero no toda su obra-. El resto es un desierto no se sabe bien de qué. Como el propio Gil de Biedma no da ninguna explicación para este extraño fenómeno estamos legitimados para suponer que se trata simplemente de que la teoría de

9 Esta interpretación novelesca de la poesía tardía de Espronceda se basa, entre otros argumentos, en testimonios de la época, como el que el editor, Ignacio Boix nos da en el Prospecto que antecede a El diablo mundo:

Sólo diremos que pertenece a un género absolutamente nuevo en España, y que tiene también muy pocos puntos de contacto con los géneros de literatura que han cultivado los más célebres poetas.

Robert Marrast también interpreta a Espronceda en la línea de la poesía de la experiencia, "presentada directamente, a partir de hechos reales, cotidianos, localizados con precisión en un universo familiar a su lector (...). Para ello, usa de los recursos que le ofrecen los varios géneros de la ficción literaria empezando por la novela...» (MARRAST, 1978: 48). Ciertamente no siempre la novelización de la lírica se halla apoyada en testimonios tan claros. 
Langbaum se adapta mal a la poesía española. Esta conclusión nos lleva directamente al segundo repaso: las deficiencias en la fundamentación de la teoría langbaumiana.

El método de Langbaum para caracterizar las dos edades de la poesía resulta el contrario al que un buen sentido analítico recomendaría. Caracteriza en primer lugar la edad moderna y la edad clásica aparece definida por contraposición. De esta manera resulta fácil caer en impresionismos o incomprensiones al no haber tomado una distancia suficiente con el objeto del análisis. El resultado de esta inversión analítica es una visión del Romanticismo con materiales del siglo XX. En general, todo el siglo XIX es visto por Langbaum como la anticipación del siglo $\mathrm{XX}$. Vitalismo y relativismo, los principios del siglo $\mathrm{XX}$, son trasladados al siglo XIX. La puesta en cuestión de la idea, frente a la certeza $o$ cualquier otro producto empírico, y la exaltación de toda vivencia individual de todo proceso material-corporal, son rasgos del pensamiento de este siglo $-\mathrm{y}$ de su pensamiento poético, naturalmente-, no atribuibles al siglo anterior. Langbaum equipara «juicio» y «simpatía» como dos actitudes paralelas, cuando el enjuiciamiento es la característica del sujeto decimonónico, al que su individualismo lleva a criticarlo todo y la empatía es la característica del sujeto moderno que, dominado por el relativismo, no se atreve a juzgar a nadie. Intimamente ligado a esta actitud acrítica se da el cuestionamiento de cualquier proceso racional reflexivo como problemático, término que emplea el propio Langbaum. Sobre estas premisas Gil de Biedma sólo ha podido ver en el XIX aquello que era trasladable al $\mathrm{XX}$ sin una notable desfiguración, e incluso en el $\mathrm{XX}$ tiene que negar lo que no parece entroncar con un planteamiento que en la versión biedmiana resulta demasiado estrecho.

\section{La disolución del canon lírico}

Y, a pesar de todo lo dicho, existe una profunda verdad tanto en la teoría de Langbaum como en la apreciación de Biedma. Una línea esencialmente moderna fluye desde el Romanticismo a la actualidad en los géneros líricos, sólo que ese flujo transcurre a mayor profundidad que fenómenos temáticos como los derivados de la experiencia vital con los que tiene, por supuesto, algo que ver. Ese flujo, ese fenómeno, tiene un cariz puramente estético, aunque sus manifestaciones sean muy variadas - y las haya temáticas y compositivas-: se trata de la desintegración del canon lírico. 
El fenómeno de la desintegración del canon lírico nos enfrenta a la sacralidad poética sub specie aeternitatis, porque la desintegración del canon lírico significa la pérdida de esa sacralidad poética, la pérdida de la condición eterna de la palabra poética. Esta pérdida se produce - como ha explicado M. Bajtín- como un fenómeno de atracción de la novela sobre los demás géneros, los géneros canónicos, fenómeno que Bajtín denomina novelización. Pero novelización no significa que los demás géneros adquieran características novelísticas. No se trata de que determinadas pautas literarias experimentadas primero en la novela se trasladen a la lírica o a los demás géneros, sino la disolución de los elementos esenciales de cada género. Al ser la novela un género sin canon - sin más canon que la más libre imaginación y libertad creadora y el compromiso con la actualidad viva-, su enorme libertad atrae a los demás géneros que entran en una nueva era. Esta era se caracteriza por dar entrada al presente, a la actualidad viva, en el ambiente cerrado y enrarecido de los géneros canónicos, entre otras cosas.

Los primeros síntomas de la disolución - gradual, pero no lineal- del canon lírico se experimentan en el Romanticismo y Espronceda es, ciertamente, un precursor, ese es su mérito:

aunque los románticos se proponían hacer de su obra, lo mismo que los poetas posteriores, la expresión de una experiencia individual, y aunque esa experiencia - que en última instancia no es otra que la de vivir en una sociedad que nosotros llamamos industrial y ellos llamaban prosaica - sustancialmente no haya variado, sí que han variado el valor y la significación que el poeta le atribuye $y$, en consecuencia, la manera de formularla. Los románticos ven en ella, precisamente porque son capaces de expresarla, la encarnación de la experiencia y de la conciencia de la Humanidad, y, si son progresistas, como lo era nuestro poeta, de la Humanidad en marcha, es decir, de la sociedad. «La poesía es la expresión del estado moral de la sociedad», según afirmaba Espronceda en una de sus lecciones en El Liceo (El pie de la letra, 277).

Gil de Biedma ve perfectamente que Espronceda es el primer poeta moderno, porque establece un tipo de relación nueva - sobre todo, en poesíacon el presente. Esa relación le lleva a escribir poemas novelizados como $E l$ estudiante de Salamanca o El diablo mundo, expresión de lo que en la época se llamó «poesía filosófica».

En el caso de los poetas del alma, como son Bécquer y Unamuno, la disolución del canon lírico se expresa más bien por sus esfuerzos de refundación de 
un canon para el que tienen sus propias propuestas, salidas siempre del alma - «Hay otra (poesía) natural, breve, seca, que brota del alma como una chispa eléctrica...», decía Bécquer y, a propósito del endecasílabo libre, Unamuno hablaba del «que se pone a escribir porque el alma le pide versos, le demanda expresiones rítmicas de sentimientos fugaces...»- y fundadas, entre otros recursos, en la música y el ritmo.

En Cernuda, por limitar este repaso a los poetas propuestos por el propio Biedma, la expresión de la disolución del canon lírico adopta diversos aspectos, todos ellos problemáticos. La ironía, la palabra dual, la autorreflexividad -el uso de la segunda persona - monologal, etc., son cuestiones que hereda Biedma y que, en él, podemos analizar con mayor detenimiento.

Antes de pasar al análisis conviene aclarar algunos extremos de la visión sumarísima de la disolución del canon lírico. En primer lugar, hay que tener presente que la base de este fenómeno estético es un fenómeno histórico-literario: literario, porque se debe a la institucionalización de un género nuevo, la novela, que descompone el equilibrio existente entre los viejos géneros; histórico, porque esa institucionalización no es un hecho casual e irrelevante, expresa la germinación en el plano estético de una nueva etapa histórica: la de la crisis del hombre occidental, crisis de madurez del conjunto de la Humanidad. En la medida en que se trata de un fenómeno histórico de alcance universal, afecta - aun de forma muy desigual - a todos los poetas contemporáneos - y a cualquier cultivador de un género estético, aun en el caso de las artes plásticas-.

El tipo de influencia que tiene la disolución del canon en cualquier género literario es profunda, proteica y polifacética. También estas características se dan en el caso de la poesía. Nada en poesía moderna puede verse libre del cuestionamiento enfermizo que la pérdida de la sacralidad lírica supone. Ni los materiales —rima, ritmo, métrica, lenguaje, etc.-, ni los temas -la retórica del elogio tradicional-, ni las formas artísticas - eso que los poetas llaman el tono y que harían mejor en llamar el género-, pueden permanecer insensibles a la revolución de los géneros. Tampoco el poeta y el destinatario pueden ser ya los mismos. Todo está sujeto a la vorágine del desequilibrio, de la modernidad, a un cuestionamiento implacable, producto de la desintegración definitiva del viejo mundo de valores estables.

Al hablar, pues, de retomar elementos procedentes de la novela, de refundación de la lírica, de la introducción de la ironía, de la palabra dual, etc., como exponentes del proceso de disolución del género lírico, no pretendo otra cosa que conseguir un cierto entendimiento, un cierto compromiso, entre las implicaciones - apenas entrevistas - de esta teoría y determinadas certezas de la ciencia literaria actual que apuntan en esa dirección. Todos estos problemas re- 
quieren otro tratamiento del que, en este marco, puedan recibir y, aquí, sólo tiene cabida un leve apunte de los problemas enfrentados.

\section{Semiótica de la experiencia}

Volvamos, pues, a Gil de Biedma, hechas estas inaplazables precisiones. Y este regreso, quizás ya definitivo, nos va a llevar, por fin, a la contemplación del papel que espacio y tiempo juegan en su arquitectura poética.

La primera cuestión es hasta qué punto en un poeta plenamente consciente de la (y de su) modernidad la lucha entre el pasado absoluto y el presente actual está viva todavía. Esta lucha caracteriza a los poetas que se han cuestionado su vinculación con la modernidad, y en Biedma la lucha entre el pasado absoluto y el presente adquiere una formulación bien precisa: la lucha entre el Unigénito, el hijo de Dios, y el hijo de vecino. En su artículo «¿Adónde el paraíso, sombra,/tú que has estado?», Biedma explica cómo le apasiona la posibilidad «de indagar en el íntimo paraíso imposible, e intransferible, cuya nostalgia acompaña a cada cual a lo largo de su vida, como una sombra». El presente es «intratable a estos efectos», y, por ello, la visión paradisíaca sólo puede tener dos dimensiones temporales: el pasado o el futuro. El futuro es descartado de inmediato porque lleva a la utopía y al colectivismo. El pasado, en cambio, lleva a la edad de oro ${ }^{10}$.

10 T. S. Eliot ha sido lúcido en este aspecto. Sus comentarios a la heroificación moderna del Ulysses de Joyce hacen entrever su posición frente a este problema:

In using the myth, in manipulating a continuous parallel between contemporaneity and antiquity, Mr Joyce is pursuing a method which others must pursue after him... It is simply a way of controlling, of ordering, of giving a shape and a significance to the immense panorama of futility and anarchy which is contemporary history (...). Instead of narrative method, we may now use the mythical method. It is, I seriously believe, a step toward making the modern world possible for ant, toward that order and form which Mr Aldington so earnestly desires (Citado por LangBaum, en The Poetry of Experience, pp. 10-11).

Como puede apreciarse, también Eliot encuentra una vinculación entre la cuestión del tiempo y el problema de la novela (narrative method) junto al que coloca la solución del método mítico. El comienzo de «Burnt Norton», en Four Quartets, afronta de forma explícita esta cuestion:

Time present and time past

Are both perhaps present in time future, 
Las edades de oro (...) incluso cuando se identifican con algún momento histórico legendario, son proyecciones de la nostalgia personal de un hombre, o de todos los hombres. Los paraísos pretéritos son líricos esencialmente. Uno quiere volver a la infancia, por supuesto, pero de otra manera (...). Es L'enfance retrouvée a volonté (El pie..., 195-196).

En el Retrato... Biedma pasa revista a su experiencia del tiempo, que, como se verá a continuación, está íntimamente ligada al espacio. Este tema reaparece en diversos momentos del diario, pero la siguiente secuencia constituye una meditación completa sobre el tema y nos presenta todos los matices con la profundidad de que Biedma es capaz:

La intensidad ya no es la misma, pero mis musings de estos días siguen dándole vueltas a la impresión del regreso. Sentimiento del tiempo que casi había olvidado desde que empecé a trabajar, igual al de la adolescencia, cuando me decidió a escribir versos. De los diecinueve a los veintitrés años estuve obsesionado por el pasado.

Pienso que el orden que tienen en la Nava los recuerdos, completamente distinto al de Barcelona, es anacrónico y refleja una experiencia mía del tiempo que ya no es la actual. A los veinte años viví mi último verano aquí, mi última larga temporada de Hijo de Dios; los regresos después no han sido más que intentos de regreso, han añadido muy poco. La imagen de mi vida en la Nava quedó completa hace seis años y al volver ahora trae con ella un modo de sentir el tiempo que era el mío en el verano de 1950.

Más que el paso del tiempo, me preocupa ahora, en Barcelona, el paso de la edad. Entonces me obsesionaba la idea de momentos vividos que creía imborrables: mi relación con el pasado era propiciatoria y religiosa, se nutría de una instintiva esperanza de volver a él. Esperanza, por ejemplo, de volver a mayo de 1948 . Aún no había formado un sentimiento específico del tiempo y lo suplía con mi experiencia sentimental del espacio -es decir, de las distancias y de las separaciones-, que se adquiere muy pronto. Proust es muy inteligente cuando

And time future contained in time past.

If all time is eternally present

All time is unredeemable.

Bajo el sentido religioso que la crítica ve en estos versos hay también y, quizá, especialmente, una reflexión sobre el problema estético fundamental — para un poeta--: cómo salvar la modernidad. 
reconstruye toda la mitología de su infancia en función de dos direcciones simbólicas en un espacio concreto: le caté de chez Swann y le côté de Guermantes. La experiencia sentimental del espacio sirve de primer molde al sentimiento del tiempo.

Si transferimos al tiempo nuestra experiencia sentimental del espacio -que además es en gran parte mágica, porque es muy temprana- aquél queda por definición dotado de reversibilidad: es recorrible en todas direcciones. Igual que en una gran ciudad desconocida pasamos y repasamos por dos o tres lugares célebres, que nos sirven de referencia cada vez para ir a distinto sitio, yo presentía el futuro como un ámbito dentro del cual me orientaría volviendo a encontrar ciertos momentos... Era sólo cuestión de estar alerta, sabiendo qué buscaba, y de propiciar la suerte $\longrightarrow$ sea, de observar ritos-.

El regreso era posible. Luego era capital conservar todo en orden -cada recuerdo en su fecha, cada imborrable imagen en su brillo-, a la espera de vivirlo otra vez. En esto aún me reconozco: mi memoria está siempre ordenada y dispuesta como si mañana hubiera de consultarla el Creador, aunque ya he conocido al vendaval y sé que fijar, limpiar y dar esplendor es por completo inútil. Adoraba el pasado porque parecía inmóvil, porque le creía permanente como el libro leído que se coloca en el estante. No lo es, está en perpetuo movimiento, es de un horrible dinamismo. Nuevos recuerdos a cada instante ingresan en su ámbito, desplazando a los viejos. Cuando éstos vuelven son algo magmático, un sabor elemental e indefinido. De qué sirve que regrese la exaltación que conocí aquella noche de 1948, al pie de la escalinata de la Iglesia de Sitges, junto al mar, si ya no sé que es ella. Lo que yo adoraba era el momento aquél, no el sabor de un sabor a sí mismo (Retrato..., 148-9).

Como vemos, admite tener Biedma dos sentimientos del tiempo: el viejo y poético de la exaltación religiosa del pasado y el actual, específico y prosaico. Un tercer tiempo, el tiempo de la misma reflexión, del musing podemos palparlo distinto de los otros dos.

La primera percepción del tiempo es la percepción poética clásica. La percepción «de la adolescencia; cuando me decidió a escribir versos». Es la obsesión por el pasado, adorado «porque parece inmóvil, porque le creía permanente como el libro leído que se coloca en el estante». Esta visión del tiempo es la de los clásicos, el tiempo perfecto, acabado, elevado. La imagen del libro leído y devuelto al estante es certerísima: un mundo cerrado, superior, ordenado. Este mundo, este espacio-tiempo, es el de la Nava: «la imagen de mi vida en la Nava qued6 completa hace seis años»; es la imagen, como dice en la secuencia siguiente (p. 150), del paraíso. Paraíso que ya fue perdido en la infancia —on 
ocasión de la guerra, y que será definitivamente perdido «desde que empecé a trabajar». La experiencia del paraíso, de los momentos imborrables, sólo puede tener su expresión estética en el dominio de lo sagrado, en el género de la palabra poética. La idea de la sacralidad es subrayada por el propio Biedma al caracterizar su relación con el pasado como "propiciatoria y religiosa», nutrida de «la instintiva esperanza de volver a él».

La voz - la persona - que surge de ese mundo sagrado es la de Narciso: el Unigénito. La única personalidad que puede proveer un mundo perfecto es la del hombre de los recuerdos, perpetuo anhelante del regreso a ese mundo. Y, pese a que esta personalidad es negada por el Biedma del musing, como hemos visto y como después analizaremos, continuamente esta personalidad del recuerdo, este Narciso, reaparece en su obra — «y al volver ahora trae con ella [la imagen de la vida en la Nava] un modo de sentir el tiempo que era mío en el verano de $1950^{11}$. Narciso es la voz de los recuerdos pero también del sentimentalismo, el sentimentalismo que brota del paraíso perdido. Recuerdos y sentimentalismo son las dos caras de una misma realidad. También esto está dicho en el musing citado, cuando Biedma define su experiencia temporal como sustituida por una «experiencia sentimental del espacio». A propósito de esta «experiencia sentimental del espacio», Biedma insiste en el carácter mágico de esta percepción y le da dos explicaciones: «porque es muy temprana» y porque bastaba una noche de tren para pasar de un mundo prosaico -el de la rutina urbana- al mundo poético - la Nava- Una vez más la umbralidad aparece definida por Biedma con ese sentido mágico-estético.

El segundo de los mundos descritos en el musing es el mundo prosaico de Barcelona, del trabajo. Es el presente. Y su espacio es el infierno, el reino de lo vulgar y de lo cotidiano, como sus realidades, dependencias y satisfacciones. La experiencia que tiene Biedma de este espacio es la de una prisión: siempre cerrada, aislada. Así define Barcelona en la página 123 - ya citada - del Retrato... La cotidianidad refuerza esa sensación de cierre y aislamiento:

sólo el hecho de sucederse presta a mis días una ilusión de coherencia (Retrato..., 34).

Y la persona que habita este mundo cerrado y asfixiante no puede ser otra que el rebelde Calibán, el hijo de vecino. Un Calibán que se aburre:

11 Recuérdese la penúltima frase de la solapa de Las personas del verbo: «QQue hace un chico de 1950 como tú en un año indiferente como este?» 
Aburrimiento. No hay en toda esta ciudad nadie por quien me valga la pena trasnochar (Ibid, 133),

que se entrega al alcohol y al sexo, y cuya conducta amenaza al poeta:

Mi larga privación sexual empieza a pesarme. Ráfagas de calentura aguda - sobre todo después de comer- que me esfuerzo en localizar antes que suban a la cabeza y se conviertan en obsesión. Si no, adiós poemas y adiós ensayo sobre Guillén... (Retrato..., 162).

Te acompañan las barras de los bares

últimos de la noche, los chulos, las floristas

(de "Contra Jaime Gil de Biedma»).

Para Biedma, el mundo prosaico y adulto le produce «un sentimiento específico del tiempo». Y este sentimiento específico procede de un mundo en perfecto movimiento, de un horrible dinamismo, radicalmente enfrentado al mundo estático de Narciso.

Pero, frente al mundo poético y al mundo prosaico, e igualmente distante de ambos, hay un tercer mundo: el mundo del ideólogo y del moralista, el mundo que integra la reflexión, el musing, prosaico o poético. Es el mundo en el que se establece el rapprochement entre Narciso y Calibán. «De regreso en Itaca» está dominado por este espacio-tiempo, el del tono reflexivo. En este espacio de reflexión los recuerdos «son algo magmático», relativo. También el deseo calibanesco es dominado. Es un espacio y un tiempo para la ironía, arma que vence tanto el recuerdo como la pasión. Este espacio-tiempo también es poético, pero en un sentido muy distinto del tradicional. Se trata de mundo poético moderno. Esto significa dos cosas. En primer lugar, que el espacio no es un paraíso - tampoco el infierno de la vida cotidiana-, ni tan siquiera perdido. El espacio de la meditación es el Purgatorio - la Nava que sirve de reposo y convalecencia-, es el espacio en el que la experiencia particular y concreta puede segregar «un sentido general, parecido a una moraleja» ${ }^{12}$. En segundo lugar, que el tiempo ni es el pasado absoluto del canon lírico o de esa experiencia mágica de la Nava-Paraíso, ni el presente carcelario del infierno-Barcelona. Se trata de un tiempo abierto al pasado, del que acepta el recuerdo; y al presen-

12 Estas palabras son de J. GLl DE BIEDMA y están contenidas en la entrevista que se incluye en Infame Turba, p. 243. El sentido concreto que tiene en la entrevista va referido a los poemas de Moralidades. 
te, del que sufre el impulso vitalista. Incluso se abre al futuro, con la virtualidad de la moraleja, pero también con la apertura, la imperfección -en el sentido de inconclusión- de la risa callada, de la ironía.

Tres voces, tres mundos, constituyen el fundamento de la creación literaria biedmiana. Esta noción que ya nos era conocida por el testimonio del propio poeta, ha adquirido ahora su extensión espacio-temporal. Quizá sea conveniente que volvamos a la cuestión inicial: cómo puede ser moderna la poesía moderna. «El tema fundamental de toda la poesía moderna - afirma Jaime Gil de Biedma - es intentar explicar la relación con lo sagrado personal» ${ }^{13}$. Resulta equívoca esta respuesta y no es de extrañar que haya fomentado interpretaciones poco afortunadas. Auden -cuyo eco se percibe en esa frase biedmiana - andaba más acertado al explicar los grandes cambios del estilo artístico por corrimientos en la frontera que limita «lo sagrado de lo profano en la imaginación de una sociedad» (Auden, 1948: 67). En esta frase queda mejor definida la relación entre lo sagrado y lo prosaico: una relación de lucha, en la que lo sagrado lleva las de perder desde el Romanticismo en Europa, en realidad, desde la Ilustración, como dice Langbaum. Desde este punto de vista es posible entender la frase de Biedma. Para Biedma y su tiempo lo sagrado apenas sobrevive en los límites del recuerdo, de la ya concluida adolescencia. Recuerdo y adolescencia pertenecen a la mitología particular biedmiana, pero comparten con nuestra época -con Eliot, con Auden, con Cernuda y con Gil-Albert- el retroceso de lo sagrado a una condición residual ${ }^{14}$.

13 La frase está citada en Rovira, 1986: 13.

14 Rovira ha explicado el problema de la mitificación con una argumentación en parte coincidente y en parte divergente con la que aquí se expone. Dice Rovira:

El poeta ha dicho del mito que es:

Una especie de abreviatura universal de la experiencia; una explicación de lo que somos en términos de lo que no hemos sido y ya no seremos nunca.

Y en uno de sus poemas habla de su «imposible propensión al mito", pues bien, su actitud se mueve precisamente entre el mito y la desmitificacion: si se trata de encontrar lo sagrado personal, algo que dé sentido y coherencia a la propia vida, se impone una exigencia radical en esa búsqueda: la cuestión no es construir un «paraíso» donde hallar el refugio, sino encontrar una «identidad", y esa identidad requiere la desmitificación, la irrupción de lo real en el mito para averiguar cuál es su grado de irrealidad, para «no engañarse ni engañar». En este sentido, la actividad poética adquiere matices de crueldad, de autocastigo (...), aun desvelado, sometido a la ironf́a, el mito sigue ejerciendo su poder en forma de nostalgia... (es, como todo el mundo sabe, el viejo pro- 
La consecuencia del retroceso de lo sagrado es el abandono por el discurso poético de la retórica del elogio. El motor de la poesía, tanto en la Grecia preclásica, como en los albores de la Edad Media europea es la retórica del elogio: en unos casos laico y en otros divino - sobre todo en la antigua lírica religiosa europea-. En el mundo moderno, en el que lo sagrado es residual, la poesía debe vivir en la frontera con otros géneros, ya que su dominio, otrora espléndido, se ha agostado.

blema de los Reyes Magos: averiguar que no existen puede implicar desear más ardientemente su existencia). (RoviRA, 1986: 100).

Afirmar que la actitud de Biedma se mueve entre el mito y la desmitificación supone una concepción muy similar a la lucha expuesta entre el pasado absoluto representado en Narciso y el presente voraz de Calibán. Lo que no concuerda con esta interpretación es esa oposición entre el "paraíso" y la «identidad", cuya lógica permanece inexplicada. Sí que hay un problema de identidad en Biedma, pero no se puede disociar de su «imposible propensión al mito». 


\section{REFERENCIAS BIBLIOGRÁFICAS}

AUDEN, W. H. (1948): The Dyers's Hand. Citado por la traducción española: La mano del teñidor, Barcelona, Barral, 1974.

BAJTIN, M. M. (1975): Voprosy literatury i esteteki. Moscú, Judozhestvennaia Literatura. Traducción española: Teoría y estética de la novela. Madrid, Taurus, 1989.

CAMPBELL, Federico (1971): «Jaime Gil de Biedma o el paso del tiempo». Infame turba. Barcelona, Lumen.

DRONKE, P. (1968): The Medieval Lyric. Traducción española: La lírica medieval, Barcelona, Seix-Barral, 1978.

Greimas, A. J.;FOnTANILlE, J. (1991): Sémiotique des passions. Des états de choses aux états d'ame. París, Seuil.

Hamburger, K. (1957): Die Logik der Dichtung. Munich. DTV Klett-Cotta, 1987.

HEGEL, G. W. F. (1835): Vorlesungen über die Aesthetik. Traducción española: Estética. Barcelona, Alta Fulla, 1988.

JiMÉNEZ, José Olivio, (1972a): «Una versión realista de la irrealidad: sobre Jaime Gil de Biedma y su libro Moralidades (1966)», en Diez años de poesía española. 1960 1970, Madrid, Ínsula.

- (1972b): Cinco poetas del tiempo, Madrid, Ínsula.

- (1991): «Borrar, borrarse: la escritura poética de Jaime Gil de Biedma», ponencia leída en el Congreso «Jaime Gil de Biedma y su generación poética», Zaragoza, 1991. 
JimÉnEZ MiLlán, Antonio (1986): «La ciudad en el tiempo (Notas sobre la poesía de Jaime Gil de Biedma)». Litoral, 163-165, pp. 102-106.

Langbaum, Robert, (1957): The Poetry of Experience. The Dramatic Monologue in Modern Literary Tradition, Chicago y Londres, The University of Chicago Press, 1986.

MARRAST, Robert, (1978): «Introducción crítica», en J. DE ESPRONCEDA, El estudiante de Salamanca. El diablo mundo. Madrid, Castalia, 1978.

ManginI, Shirley, (1980): Gil de Biedma, Madrid, Júcar.

Rovira, Pere, (1986): La poesía de Jaime Gil de Biedma, Barcelona, Edicions del Mall.

SANGER, Richard, (1986): «La codificación del sueño: el héroe en la poesía de Jaime Gil de Biedma», Litoral, 163-165, pp. 92-98.

TODOROV, T. (1987): "L'origine des genres", La notion de la littérature et autres essais, París, Seuil, pp. 27-46. Traducción española: «El origen de los géneros», en M. A. GarRido Gallardo (comp.), Teoría de los géneros, Madrid, Arco Libros, 1988.

TomaChevSki, Boris (1928): Teorija literatury. Poetika. Leningrado. Traducción española: Teorta de la literatura, Madrid, Akal, 1982.

Obras citadas de JAIME GIL DE BIEDMA: Las personas del verbo. Barcelona, Seix-Barral, 1982. Retrato del artista en 1956. Barcelona, Lumen, 1991. El pie de la letra. Barcelona, Crítica, 1980. 